\title{
The No-Participation of Students in Physical Education: A Comparative Study of Tunisian Trainee Teachers
}

\author{
Naila Bali \\ ISSEP Ksar Said University, La Manouba, Tunisia \\ Email: naila_bali@yahoo.fr
}

Received 29 January 2016; accepted 11 July 2016; published 14 July 2016

Copyright (C) 2016 by author and Scientific Research Publishing Inc.

This work is licensed under the Creative Commons Attribution International License (CC BY). http://creativecommons.org/licenses/by/4.0/

(c) (i) Open Access

\begin{abstract}
Although most students are conscious of the benefits of physical activity, there is a small proportion that practices sufficiently physical activity. Firstly, our studies aimed to find out the degree of importance of the problematic of no-participation of students in physical education. For this reason, we based our analysis on a questionnaire consisting of eighteen questions that were variables to clarify the latent construct "the no-participation of students". The value of Cronbach alpha index is 0.723 . For this, we had used a questionnaire consisting of eighteen variables in order to find out the degree of importance of the variables associated to the no-participation of students. Our data were collected in the end of the course with 150 physical education student teachers (PE-STs) at the Higher Institute of Sport and Physical Education (ISSEP) in Tunisia. They are all mixed classes of Level 1 and 2 (first and second year of secondary school) teachers. These questions are constructed to give the PE-STs the opportunity to distribute their responses to the no-participation variables such as the physical complex, motivation, hourly, Injury, study sector, teacher Characteristics, external influences, and relationship with other students, infrastructure, lesson content and sport taught. The major response of PE-STs response is in the following order: 1) Teacher Characteristics (72.7\%), 2) Relationship with other students and Motivation (69.3\%), 3) Relationship with teacher $(66.7 \%)$.
\end{abstract}

\section{Keywords}

Professional Training, Student Teachers, Students, No-Participation

\section{Introduction}

The analysis of the tutorial activity took an interest in the field of professional training (Maela, 2009; Desbiens, 
2009; Perez-Roux, 2012) and in the Higher Institute of Sport and the physical Education (ISSEP) in Tunis (Bali, 2005; Bali, 2013; Bali, 2014; Bali, 2015; Zayed, 2015) but few studies analyzed physical inactivity among students which is already a problem that is growing internationally. According to Cloes (2013), a physically educated person can be recognized as someone who is physically active, who knows the implications and benefits of participating in the physical activity and gives value to physical activity and its contribution to enjoy a healthy lifestyle.

According to Lemoyne and Valois (2014), the role of physical education proves to be a key step where students must make important decisions about their lifestyle. Over the last twenty years, it has been shown that regular physical activity provides undeniable benefits to the health of the population (Bouchard \& Shephard, 1994).

Warburton et al. (2007) established detailed recommendations concerning the required dosage to issue health benefits. National recommendations in terms of physical activity practice suggest a regular basis (more than 3 times per week), with a sufficient long duration (30 - 60 minutes per day) and at varying intensities.

Degrandpré and Paquet (2006) suggest that sufficient physical activity practice contributes to better stress management, satisfactory mental health as well as improved academic performance.

However, according to Nolin and Hamel (2005) current data on students' physical activity practices reveal worrying figures. Even though the percentage of active young adults seems to have increased between 2000 and 2005 (from 19.9\% to 30.8\%), there are only 59\% of this population that reaches the recommended level of physical activity.

Nolin and Hamel (2005) demonstrated that girls between 15 and 24 years show a considerable decline (over $15 \%)$ of young people who are sufficiently active.

According to Beckers et al. (1995), the problems faced by PE-STs are related to the class management and the material conditions, the conception of activities, the participation of students, and to the relations between the teaching staff and the pedagogical action.

According to Bégin (2011), the loss of time at the beginning of physical education course during the instructions and between activities demotivate the adolescents. Some adolescents said they learned only few things during their physical education lessons. According to them, if there was no time wasting, they would be more motivated to participate more actively and would avoid absences.

Boissonneault et al. (2007) grouped the factors of school dropout in four dimensions interacting one another. The first dimension is the school environment that treats the climate and the atmosphere prevailing in school. The second is the curriculum and learning environment that focuses on academic aspects (the contents) and on teaching. The third and fourth dimensions are the home environment and community environment which are outside the school setting and focus on the environments in which the student lives.

The objective of this study is to highlight the conception of PE-STs of the no-participation of students in physical education. We will find out the degree of importance of the variables associated to this problem. I will be interested in this question in the field of the practical teaching of the PE-ST in Tunisian schools. In order to operationalize research questions, we have developed the following hypotheses: The major variables related to no-participation of students in physical education are the infrastructure and lesson Content.

\section{Methodology}

\subsection{Participants}

The participants had accepted to participate in this study 150 PE-STs (75 men and 75 girls) were selected from total 321 PE-STs who studied in the Higher Institute of Sport and Physical Education (ISSEP) Tunis (there are only 3 ISSEP in Tunisia each having their own teaching practice modality) is a public Institute in Tunisia. All participants in this study were volunteer. Participants were chosen taking into account the location of the school, the teaching level and sex of CT. They were recruited from a single Higher Institute of Sport (Tunis). The sample of participants consisted of the PE-ST (third year, BAC +3) who taught level 1 and 2 (first and second year of secondary education). All were aged between (21 \pm 1 years) registered in an introductory course to professional training in Tunisia, introductory refers to the course to practice pedagogy (introductory practicum applied to pedagogy), that is taught in the last year of the Fundamental of Physical Education License. This activity introduces the professional life that took place in schools with mixed age students (12 - 15 years old students) from a rural area in Tunis who are very engaged in professional training. The activity lasted two semesters, 
four hours per week on Tuesday or Thursday for a cumulative total time of 116 hours of teaching. Participants are not paid to participate in the research. They were not informed of the purpose and conception of the research.

Many reasons justified the choice of this sample. Firstly, this study is part of the professional training of PE-ST. Secondly; there is a social difference between the academic and professional. Thirdly, this study is part of the academic program. Our work sample meets these three parameters as indicated in the Table 1 below.

\subsection{Procedure}

Permission to conduct the current study by the University was Granted Institutional Review Board, the Tunisian Ministry of sport, the Principal of Higher Institute of sport and physical education (ISSEP) of Ksar Said in Tunis (Tunisia) (Manouba University). The researchers visited the CT and PE-STs dyads in their respective schools in order to present the purpose and design of the research and obtain written informed approval.

\subsection{The Formation of the Corpus}

We used a question to clarify the latent construct "the no-participation of students" and gave PE-STs the opportunity to share their response and concerns on issues such as the physical complex, motivation, hourly, Injury, study sector, teacher Characteristics, external influences, relationship with other students, infrastructure, lesson Content and Sports taught. The questions focus on the conception of no-participation of students by PE-STs during the internship. PE-STs are questioned while giving them the freedom to respond, and express them selvesat their ease.

\subsection{Data Collection}

Data collection was performed in two phases. The first is an interview with PE-STs in order to have data that can be useful in this study such as their age. At this meeting, we presented to the PE-STs the different steps of this research to know the phases of the questionnaire. After collecting the questionnaire data conducted with PE-ST (step 1), we conducted statistical analysis of each questionnaire response and reported it in Table 2 (step 2). This table allowed us to classify the PE-ST answers. Finally, the third step is the linkage analysis of different variables of the questionnaire.

\section{Result and Discussion}

\subsection{Result}

Eighteen responses of PE-Ss emerged from the data collected and were illustrated in Table 2: 1) Physical complex, 2) Menstrual period, 3) Motivation, 4) Age, 5) Hourly, 6) Injury, illness (without medical certificate), 7) Injury, illness (with medical certificate), 8) Study sector, 9) Season, weather in, 10) Teacher Characteristics, 11) External influences, 12) Relationship with teacher, 13) Relationship with other students, 14) Forgetting Affairs, 15) Infrastructure, 16) Influence of substances, 17) Lesson Content and 18) Sports taught.

1) The analysis of the results of the first question as shown in the Figure 1, confirms that student teachers are shared between important to very important (34\%) and (18.7\%) respectively as the variable physical complex is related to the non-participation of students in the session of physical education, (7.3\%) to (28\%) respectively are shared between not important of all and not very important, (12\%) remaining are not concerned. The analytical study of the sex variable shows no significant difference between girls and boys $\left(\mathrm{X}^{2}=0.140, P=6.917\right)$.

Table 1. Sample of Tunisian PE-ST.

\begin{tabular}{cc}
\hline Questioning & CT \\
\hline Men questioned & 150 \\
Girls questioned & 75 \\
Aged & 75 \\
Level of study & Between 20 and 22 years \\
\hline
\end{tabular}


Table 2. Data of responses of PE-STs.

\begin{tabular}{|c|c|c|c|c|c|c|c|}
\hline \multirow[t]{2}{*}{ Variables } & \multicolumn{7}{|c|}{ appreciation scale } \\
\hline & $\begin{array}{c}\text { Not } \\
\text { concerned }\end{array}$ & $\begin{array}{c}\text { Not } \\
\text { important } \\
\text { of all }\end{array}$ & $\begin{array}{l}\text { Not very } \\
\text { important }\end{array}$ & Important & $\begin{array}{l}\text { Very } \\
\text { important }\end{array}$ & $\mathrm{X}^{2}$ & $P$ \\
\hline \multirow[t]{2}{*}{ Physical complex } & 18 & 11 & 42 & 51 & 28 & 0.140 & 6.917 \\
\hline & $12 \%$ & $7.3 \%$ & $28 \%$ & $34 \%$ & $18.7 \%$ & & \\
\hline \multirow[t]{2}{*}{ Menstrual period } & 4 & 13 & 41 & 48 & 44 & 0.068 & 8.737 \\
\hline & $2.7 \%$ & $8.7 \%$ & $27.3 \%$ & $32 \%$ & $29.3 \%$ & & \\
\hline \multirow[t]{2}{*}{ Motivation } & 6 & 17 & 23 & 47 & 57 & 0.087 & 8.123 \\
\hline & $4 \%$ & $11.3 \%$ & $15.3 \%$ & $31.3 \%$ & $38 \%$ & & \\
\hline \multirow[t]{2}{*}{ Age } & 44 & 25 & 44 & 17 & 20 & 0.076 & 8.462 \\
\hline & $29.3 \%$ & $16.7 \%$ & $29.3 \%$ & $11.3 \%$ & $13.3 \%$ & & \\
\hline \multirow[t]{2}{*}{ Hourly } & 13 & 30 & 50 & 33 & 24 & 0.010 & 13.379 \\
\hline & $8.7 \%$ & $20 \%$ & $32.7 \%$ & $22.7 \%$ & $16 \%$ & & \\
\hline \multirow[t]{2}{*}{$\begin{array}{l}\text { Injury, illness(without medical } \\
\text { certificate) }\end{array}$} & 21 & 18 & 47 & 25 & 39 & 0.008 & 13.753 \\
\hline & $14 \%$ & $12 \%$ & $31.3 \%$ & $16.7 \%$ & $26 \%$ & & \\
\hline \multirow[t]{2}{*}{ Injury, illness(with medical certificate) } & 11 & 23 & 30 & 32 & 54 & 0.000 & 21.257 \\
\hline & $7.3 \%$ & $15.3 \%$ & $20 \%$ & $21.3 \%$ & $36 \%$ & & \\
\hline \multirow[t]{2}{*}{ Study sector } & 14 & 18 & 55 & 8 & 25 & 0.889 & 1.133 \\
\hline & $9.3 \%$ & $12 \%$ & $36.7 \%$ & $25.3 \%$ & $16.7 \%$ & & \\
\hline \multirow[t]{2}{*}{ Season, weather in } & 4 & 31 & 23 & 53 & 39 & 0.137 & 6.974 \\
\hline & $2.7 \%$ & $20.7 \%$ & $15.3 \%$ & $35.3 \%$ & $26 \%$ & & \\
\hline \multirow[t]{2}{*}{ Teacher Characteristics } & 7 & 24 & 10 & 46 & 63 & 0.075 & 8.484 \\
\hline & $4.7 \%$ & $16 \%$ & $6.7 \%$ & $30.7 \%$ & $42 \%$ & & \\
\hline \multirow[t]{2}{*}{ External influences } & 18 & 20 & 54 & 31 & 27 & 0.302 & 4.858 \\
\hline & $12 \%$ & $13.3 \%$ & $36.0 \%$ & $20.7 \%$ & $18 \%$ & & \\
\hline \multirow[t]{2}{*}{ Relationship with teacher } & 3 & 26 & 21 & 31 & 69 & 0.077 & 8.424 \\
\hline & $2 \%$ & $17.3 \%$ & $14 \%$ & $20.7 \%$ & $46 \%$ & & \\
\hline \multirow[t]{2}{*}{ Relationship with other students } & 3 & 19 & 24 & 51 & 53 & 0.270 & 5.178 \\
\hline & $2 \%$ & $12.7 \%$ & $16 \%$ & $34 \%$ & $35.3 \%$ & & \\
\hline \multirow[t]{2}{*}{ Forgetting Affairs } & 23 & 18 & 66 & 32 & 11 & 0.070 & 8.663 \\
\hline & $15.3 \%$ & $12 \%$ & $44 \%$ & $21.3 \%$ & $7.3 \%$ & & \\
\hline \multirow[t]{2}{*}{ Infrastructure } & 21 & 21 & 32 & 42 & 34 & 0.21 & 5.822 \\
\hline & $14 \%$ & $14 \%$ & $21.3 \%$ & $28 \%$ & $22.7 \%$ & & \\
\hline \multirow[t]{2}{*}{ Influence of substances } & 38 & 23 & 29 & 23 & 37 & 0.371 & 4.264 \\
\hline & $25.3 \%$ & $15.3 \%$ & $19.3 \%$ & $15.3 \%$ & $24.7 \%$ & & \\
\hline \multirow[t]{2}{*}{ Lesson Content } & 3 & 25 & 31 & 51 & 40 & 0.015 & 12.340 \\
\hline & $2 \%$ & $16.7 \%$ & $20.7 \%$ & $34 \%$ & $26.7 \%$ & & \\
\hline \multirow[t]{2}{*}{ Sports taught } & 5 & 31 & 48 & 37 & 29 & 0.000 & 21.702 \\
\hline & $3.3 \%$ & $20.7 \%$ & $32 \%$ & $24.7 \%$ & $19.3 \%$ & & \\
\hline
\end{tabular}

2) The analysis of the results of the second question (Figure 2) confirms that student teachers answers alternated between important to very important (32\%) and (29.3\%) respectively, concerning the menstrual period which is related to the no-participation of girls in physical education $(8.7 \%)$ to $(27.3 \%)$ respectively alternated between not important of all and not very important, $(2.7 \%)$ the remaining are not concerned. The analytical study of the sex variable shows no significant difference between girls and boys $\left(\mathrm{X}^{2}=0.068, P=8.737\right)$. 


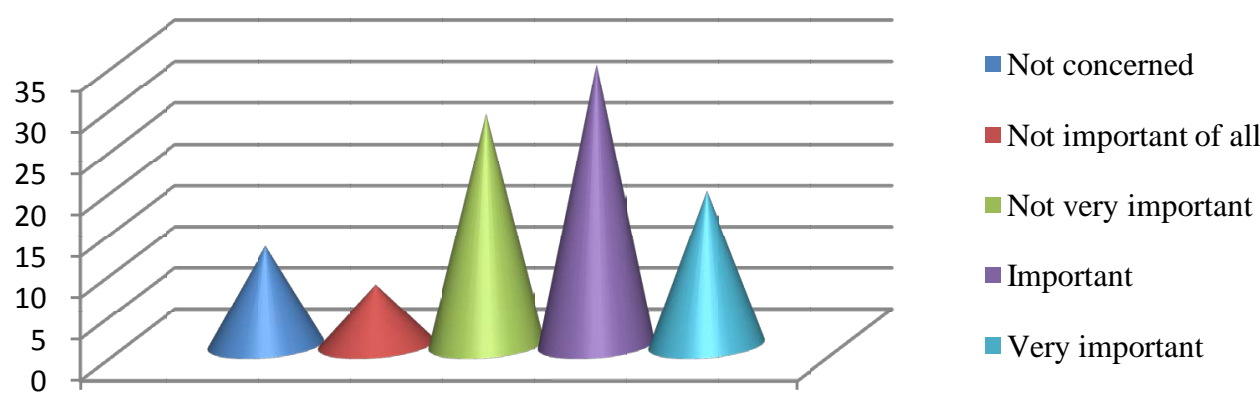

Physical complex

Figure 1. Physical complex.



Figure 2. Menstrual period.

3) The Analysis of the results of the third question (Figure 3) confirms that the majority of PE-STs answers alternated between important to very important (31.3\%) and (38\%) respectively, that the motivation is related to the no-participation of students in girls in physical education, (11.3\%) to (15.3\%) respectively, answers alternated between not important of all and not very important, (4\%) the remaining are not concerned. The analytical study of the sex variable shows no significant difference between girls and boys $\left(\mathrm{X}^{2}=0.087, P=8.123\right)$.

4) The Analysis of the results of the fourth question (Figure 4) confirms that the PE-STs answers alternated between important to very important $(11.3 \%)$ and $(13.3 \%)$ respectively, that the age is related to the no-participation of students in girls in physical education, $(16.7 \%)$ to $(29.3 \%)$ respectively, answers alternated between not important of all and not very important, (29.3\%) the remaining are not concerned. The analytical study of the sex variable shows no significant difference between girls and boys $\left(\mathrm{X}^{2}=0.076, P=8.462\right)$.

5) The Analysis of the results of the fifth question (Figure 5) confirms that the PE-STs answers alternated between important to very important (22.7\%) and (16\%) respectively, that the hour of the session is related to the no-participation of students in girls in education physics, (20\%) to (32.7\%) respectively, answers alternated between not important of all and not very important, (8.7\%) the remaining are not concerned. The analytical study of the sex variable shows a significant difference between boys and girls $\left(\mathrm{X}^{2}=0.010, P=13.379\right)$.

6) The Analysis of the results of the sixth question (Figure 6) confirms that the PE-STs answers alternated between important to very important (16.7\%) and (16\%) respectively, that the injury, illness (without medical certificate) is related to the no-participation of students in girls in physical education, (12\%) to (31. 3\%) respectively, answers alternated between not important of all and not very important, (14\%) the remaining are not concerned. The analytical study of the sex variable shows a significant difference between boys and girls $\left(\mathrm{X}^{2}=\right.$ 0.008, $P=13.7)$.

7) The Analysis of the results of the seventh question (Figure 7) confirms that the PE-STs answers alternated between important to very important (21.3\%) and (36\%) respectively, that the injury (with medical certificate) is related to the no-participation of students in girls in physical education, (15.3\%) to (20\%) respectively answers alternated between not important of all and not very important, (7.3\%) the remaining are not concerned. The analytical study of the sex variable shows a significant difference between boys and girls $\left(\mathrm{X}^{2}=0.000, P=\right.$ 21.25). 




Not concerned

- Not important of all

- Not very important

- Important

- Very important

Figure 3. The motivation.

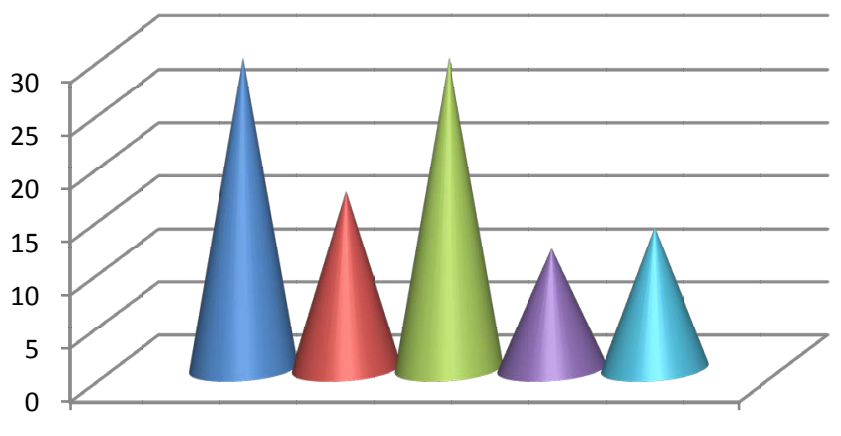

- Not concerned

- Not important of all

Not very important

- Important

- Very important

Age

Figure 4. The age.

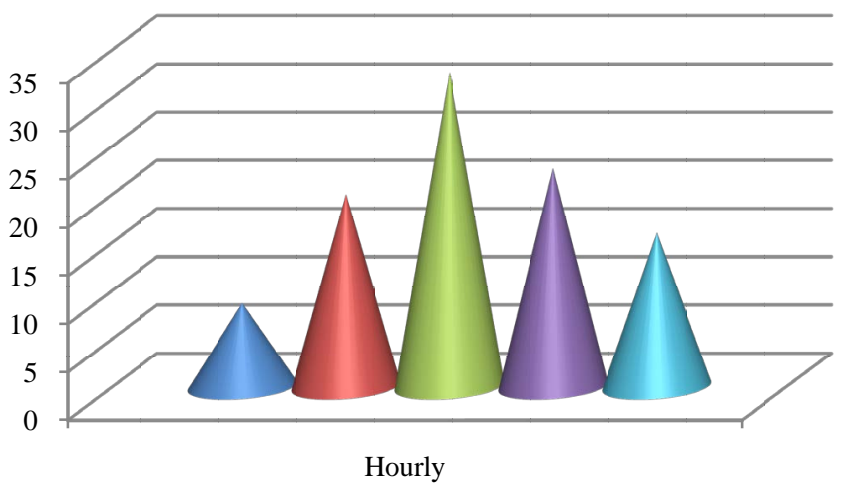

not concerned

- Not important of all

Not very important

- Important

- Very important

Figure 5. The hourly.

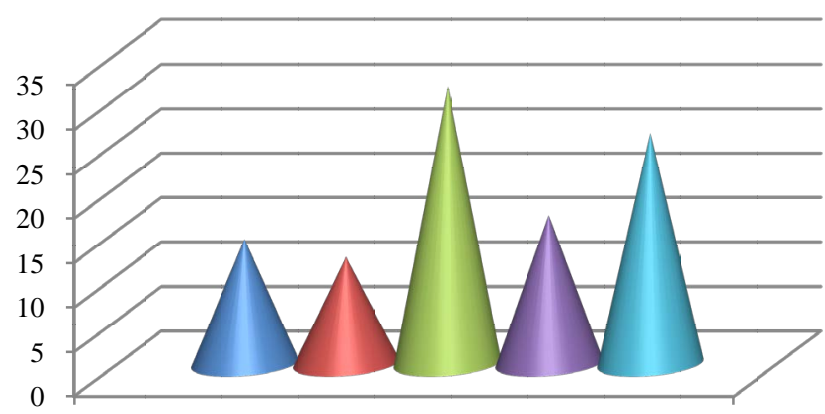

Injury, illness (without medical certificate)
- Not concerned

not important of all

not very important

- Important

- Very important

Figure 6. The injury, illness (without medical certificate). 




Figure 7. The injury, illness (with medical certificate).

8) The Analysis of the results of the eighth question (Figure 8) confirms that the PE-STs answers alternated between important to very important (25.3\%) and (16.7\%) respectively, that the study sector is related to the no-participation of students in girls in physical education, (12\%) to (36.7\%) respectively, answers alternated between not important of all and not very important, $(9.3 \%)$ the remaining are not concerned. The analytical study of the sex variable shows no significant difference between girls and boys $\left(\mathrm{X}^{2}=0.889, P=1.133\right)$.

9) The Analysis of the results of the ninth question (Figure 9) confirms that the PE-STs answers alternated between important to very important (35.3\%) and (26\%) respectively, that the season is related to the no-participation of students in girls in physical education, (20.7\%) to (15.3\%) respectively, answers alternated between not important of all and not very important, (2.7\%) the remaining are not concerned. The analytical study of the sex variable shows no significant difference between girls and boys $\left(\mathrm{X}^{2}=0.137, P=6.974\right)$.

10) The Analysis of the results of the tenth question (Figure 10) confirms that the majority PE-STs answers alternated between important to very important (30.7\%) and (42\%) respectively, that the teacher characteristics is related to the no-participation of students in girls in physical education, (16\%) to (6.7\%) respectively, answers alternated between not important of all and not very important, $(4.7 \%)$ the remaining are not concerned. The analytical study of the sex variable shows no significant difference between girls and boys $\left(\mathrm{X}^{2}=0.075, P=\right.$ 8.484).

11) The Analysis of the results of the eleventh question (Figure 11) confirms that the majority PE-STs answers alternated between important to very important (20.7\%) and (18\%) respectively, that external influences is related to the no-participation of students in girls in physical education, (13.3\%) à (36\%) respectively, answers alternated between not important of all and not very important, (12\%) the remaining are not concerned. The analytical study of the sex variable shows no significant difference between girls and boys $\left(\mathrm{X}^{2}=0.302, P=\right.$ 4.858).

12) The Analysis of the results of the twelfth question (Figure 12) confirms that the majority PE-STs answers alternated between important to very important (20.7\%) and (46\%) respectively, that the relationship with teacher is related to the no-participation of students in girls in physical education, (17.3\%) à (14\%) respectively, answers alternated between not important of all and not very important, (2\%) the remaining are not concerned. The analytical study of the sex variable shows no significant difference between girls and boys $\left(\mathrm{X}^{2}=0.077, P=\right.$ 8.424).

13) The Analysis of the results of the twelfth question (Figure 13) confirms that the majority PE-STs answers alternated between important to very important (34\%) and (35.3\%) respectively, that the relationship with other students is related to the no-participation of students in girls in physical education, (12.7\%) à (16\%) respectively, answers alternated between not important of all and not very important, (2\%) the remaining are not concerned. The analytical study of the sex variable shows no significant difference between girls and boys $\left(\mathrm{X}^{2}=0.270, P=\right.$ 5.178).

14) The Analysis of the results of the fourteenth question (Figure 14) confirms that the PE-STs answers alternated between important to very important $(21.3 \%)$ and $(7.3 \%)$ respectively, that the forgetting affairs is related to the no-participation of students in girls in physical education, $(12 \%)$ to $(44 \%)$ respectively, answers alternated between not important of all and not very important, (15.3\%) the remaining are not concerned. The analytical study of the sex variable shows no significant difference between girls and boys $\left(X^{2}=0.070, P=\right.$ 8.663). 


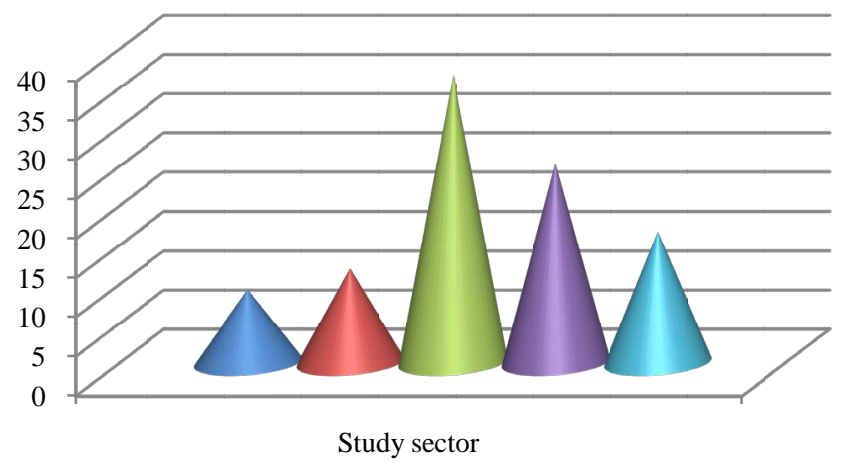

n Not concerned

- Not important of all

Not very important

- Important

- Very important

Figure 8. The study sector.

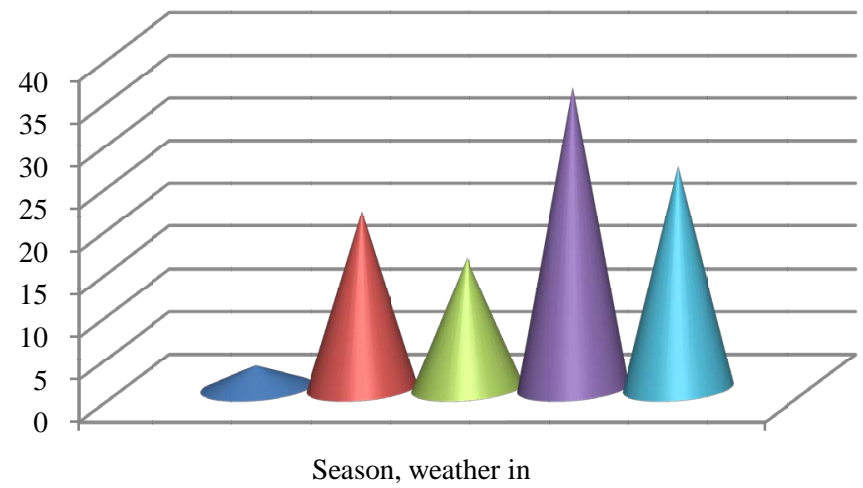

— Not concerned

- Not important of all

- Not very important

- Important

- Very important

\section{Figure 9. The season.}



Teacher Characteristics

- Not concerned

- Not important of all

Not very important

- Important

- Very important

Figure 10. The teacher characteristics.

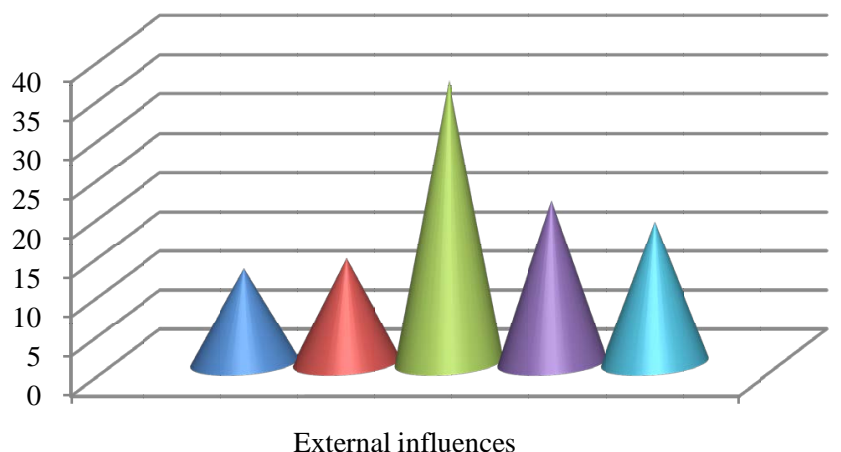

— Not concerned

not important of all

- Not very important

Important

- Very important

Figure 11. The external influences. 


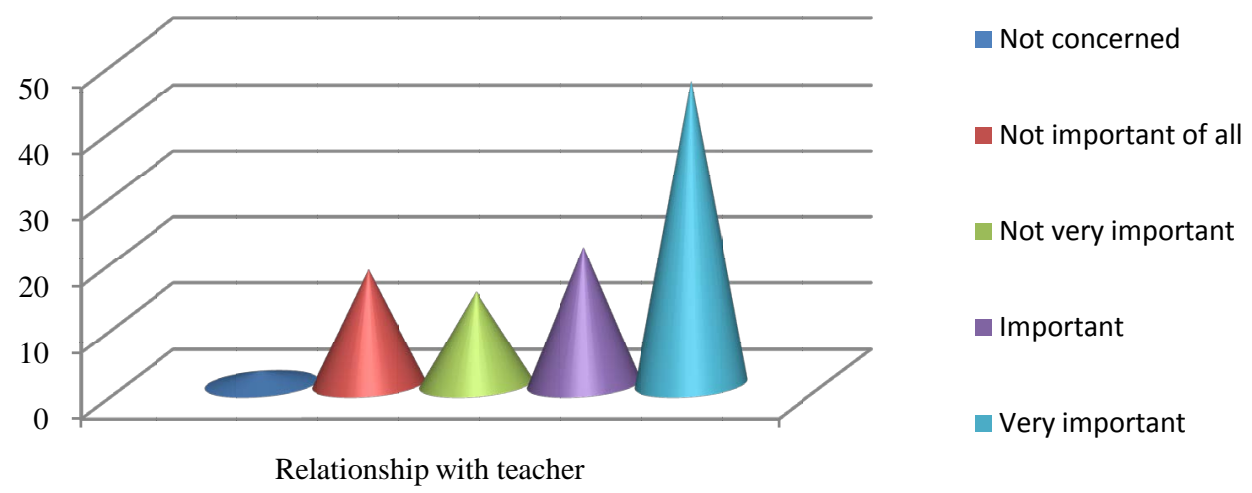

Figure 12. The relationship with teacher.

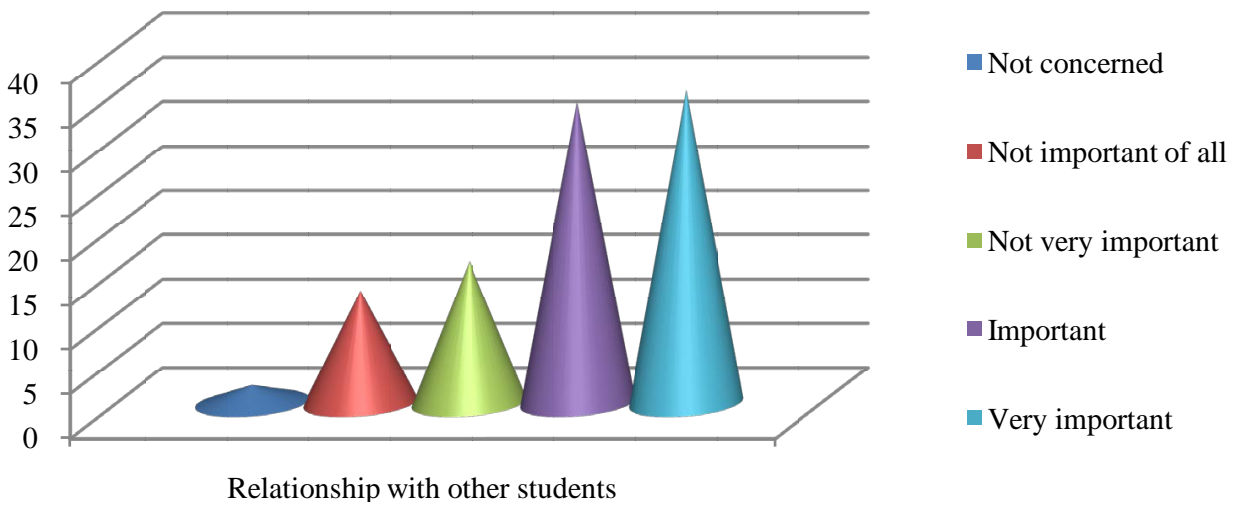

Figure 13. The relationship with other students.

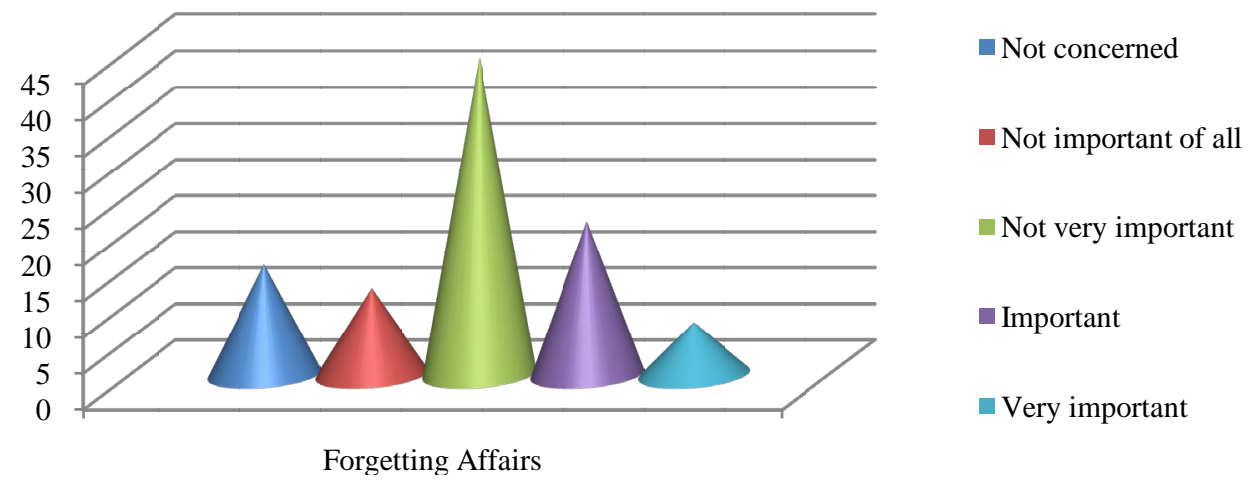

Figure 14. The forgetting affairs.

15) The Analysis of the results of the fifteenth question (Figure 15) confirms that the PE-STs answers alternated between important to very important (28\%) and $(22.7 \%)$ respectively, that the infrastructure is related to the no-participation of students in girls in physical education, (14\%) to (21.3\%) respectively, answers alternated between not important of all and not very important, (14\%) the remaining are not concerned. The analytical study of the sex variable shows no significant difference between girls and boys $\left(\mathrm{X}^{2}=0.21, P=5.822\right)$.

16) The Analysis of the results of the sixteenth question (Figure 16) confirms that the PE-STs answers alternated between important to very important (15.3\%) et (24.7\%) respectively, that the influence of substances is related to the no-participation of students in girls in physical education, (15.3\%) to (19.3\%) respectively, answers alternated between not important of all and not very important, (25.3\%) the remaining are not concerned. The analytical study of the sex variable shows no significant difference between girls and boys $\left(\mathrm{X}^{2}=0.371, P=\right.$ 4.264). 
17) The Analysis of the results of the seventeenth question (Figure 17) confirms that the PE-STs answers alternated between important to very important (34\%) et (26.7\%) respectively, that the lesson content is related to the no-participation of students in girls in physical education, (16.7\%) to (20.7\%) respectively, answers alternated between not important of all and not very important, (2\%) the remaining are not concerned. The analytical study of the sex variable shows a significant difference between boys and girls $\left(X^{2}=0.015, P=12.340\right)$.

18) The Analysis of the results of the eighteenth question (Figure 18) confirms that the PE-STs answers alternated between important to very important (24.7\%) et (19.3\%) respectively, that the influence of substances is related to the no-participation of students in girls in physical education, (20.7\%) to (32\%) respectively, answers alternated between not important of all and not very important, (3.3\%) the remaining are not concerned. The analytical study of the sex variable shows a significant difference between boys and girls $\left(\mathrm{X}^{2}=0.000, P=\right.$ 21.702).

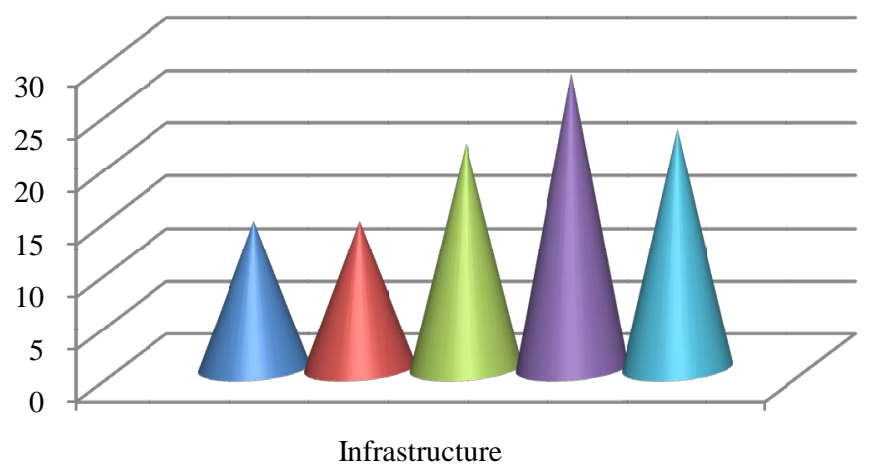

Not concerned

- Not important of all

Not very important

- Important

- Very important

Figure 15. The infrastructure.

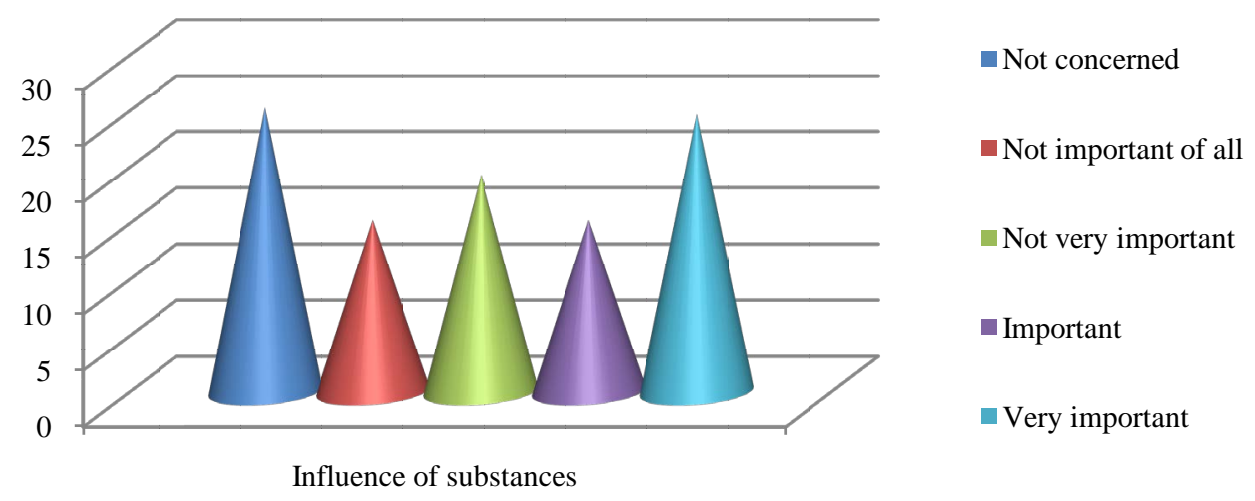

Figure 16. The influence of substances.

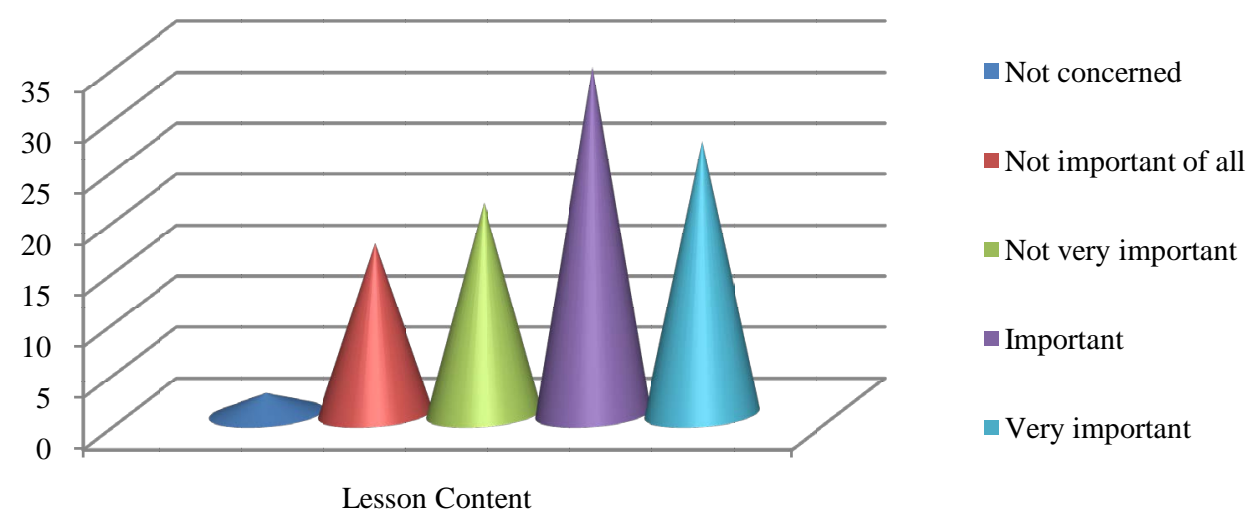

Figure 17. The lesson content. 


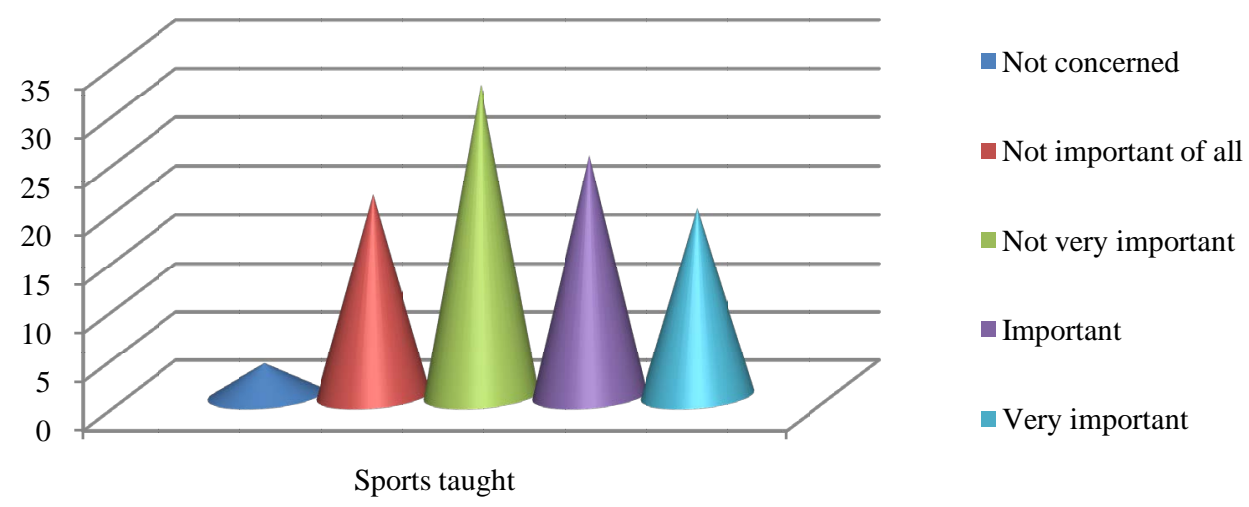

Figure 18. The sports taught.

\subsection{Discussion}

The response of PE-STs between important to very important related to different variables which are in the order: 1) Teacher Characteristics (72.7\%), 2) Relationship with other students and Motivation (69.3\%), 3) Relationship with teacher (66.7\%), 4) Menstrual period and Season (61.3\%), 5) Lesson Content (60.7\%), 6) Injury (with medical certificate) (57.3\%), 7) Physical complex (52.7\%), 8) Infrastructure (50.7\%), 9) Sports taught (44\%), 10) Injury, illness (without medical certificate) $(42.7 \%), 11)$ Study sector $(42 \%), 12)$ Influence of substances (40\%), 13) Hourly and External influences (38.7\%), 14) Forgetting Affairs (28.6\%) and the Age (24,6\%).

The results reveal that the major variable of no-participation of students in physical education is the teacher characteristics (72.7\%) of response divided between important to very important. According to Bégin (2011) the adolescents state that physical education courses are more interesting when teachers are dynamic using humor, participating in the course and are passionate about their work. Debarbieux et al. (2012) add that the encouraging attitudes are much more effective than punishment.

According to Cloes and Piéron (1989), for students, the fact of receiving a large number of corrections may be of significance through specific interpersonal relationships that develop between teachers and themselves. According to Cloes et al. (1998) during the physical education session the most fréqement problem is caused by the isolated students. Generally, teachers are interverning either by verbal remarks or punishment.

The second major variable of no-participation of students in physical education is the motivation and the relationship with other students (69.3\%) of response divided between important to very important.

Vallerand (1997) states that Depending According to the more a person experiences more fun doing an activity, the more he/she will seek to do this activity and his/her pleasure increases.

According to Bégin (2011), social aspects, fun, improvement, motor learning are important sources of motivation. It recommends that physical educators have to provide a motivating environment for adolescent girls. They should ensure that adolescent girls have fun, develop friendships and are committed.

Bégin (2011) finds that there are many important conditions for adolescent motivation in physical education sessions. They mention that the concept of pleasure must be present. Teenage girls want to feel pleasure when they do an activity. They believe that this concept should be the basis of the lesson, since they say that the physical education lesson is made to let loose and have fun.

Bégin (2011) adds that adolescent motivation can be influenced by external sources. If adolescents commit themselves to another person, their motivation will be greater because they will feel connected to that person. Moreover, the positive feedback from teachers regarding their effort and their success greatly enhances their motivation for this activity. If physical education teachers could integrate these two sources of motivation, perhaps that adolescents will be more motivated.

According to Cèbe and Goigoux (1999), motivation is a motor of learning and development because it determines the energy and attentional resources that the subject decides to grant to the processing of his/her environment. Motivation is also the product of an interaction between the characters of the learner, the task and the situation.

Regarding the relationship with other students, Moreno et al. (2007) noted that boys were perceived as being more unruly in physical education. Therefore, it seems necessary to examine the impact of students gender on the emotional reactions of teachers. 
Van Zanten (2001) indicated that the difficulties inherent in the management of conflicts with students would be in abundance on these "schools' periphery," in which teachers would implement survival strategies.

Bégin (2011) proposes to make, at the beginning of the year, socialization activities to enable girls to make friends in the course. He adds that social relations are significant sources of motivation among adolescents. The creation of opportunity to promote friendship development in physical education would be a solution to take into consideration. In addition, physical education is a subject where it is easier to generate friendships. For example, teachers could have students work in subgroup to promote social contacts.

According to Boissonneault (2007) the experiences arising from relationships with classmates impact in a positive or negative manner, the image that young people make in their school experience.

The third variable of no-participation of students in physical education is the relationship with teacher (66.7\%) whose response is divided between important to very important. According to Averill (1982), to overcome this difficulty, it is necessary to take into account the levels of students' management (social, academic, and physical education) by relating them to a group. He took into consideration the school deregulation and the ill-at-ease that can exist in a student-teacher relationship by offering levels in an integrated system: environment, the school institution, establishment and class.

According to Ayme et al. (2012) the teachers noticed that boys have more disturbing/diverting/deviating behaviors that refer to the transgression of social rules (relation to the material, relationship between students, relationship with the teacher) as for girls they rather proved disturbing behavior regarding the school rules transgression (passivity, listening, attendance and punctuality, off task). Physical education teachers have significantly noticed more disturbing behavior of boys than girls (63.6\% vs $36.4 \%)$.

Menstrual period and Season (61.3\%), Caplette (2014) notes that in girls, the starting of adolescence appears associated with a decrease in physical activity. According to Beckers et al. (1995) the problem also concerns the material conditions and the environment. For example, adapt the lesson to unforeseen atmospheric conditions.

Then we find the lesson content (60.7\%) According to Beckers et al. (1995), the observation of the teachers' and the students' behaviors and the interactions between these actors contributed to identify positive or negative variables in relation to the students' progress. He notices the problems related to the activities offered by the trainees, reverse reactions or task modification. Students seem less motivated to practice the activity either due to excessive difficulty or a lack of challenge to which the student should be faced. The proposed activities seem to be unsuitable either they are easy or difficult. There are few differences between girls and boys according to subject taught.

Coltice (2005) notes that the suggested activities during the physical education lessons are often less challenging for adolescents. The student is considered as a "biological body". That is to say, despite the sex difference, we consider that students have the same physical abilities. Most physical education lessons schedules do not take into account the type of students, but rather the constraints of equipment and premises (Coltice, 2005).

Brau-Antony (2001) showed that teachers are attached to a formative evaluation, more diagnostic, more transparent, in which students have a role to play (participatory evaluation). Cèbe and Goigoux (1999) propose that the pedagogical and didactic choices are largely based on conceptions and representations that teachers find them related to the difficulties faced by their students.

Physical complex (52.7\%), With reference to Caplette (2014), a typified male individual has traits attributed to the male biological sex that are: virility, rudeness or force. In contrast, a typified female individual has individual characteristics associated with gentleness, tenderness, compassion, grace and beauty. Caplette (2014) argues that a child learns to adjust his behavior with regards to the approval or disapproval of his perceived environmental responses. The social conception of a biological sex of a person is built through interactions with the environment.

After we find Infrastructure (50.7\%) and according to Bégin (2011) adolescents reveal that they want to be active, but unfortunately the means of action used during physical education classes are not motivating. Boucher and Morose (1990) showed that the realization of an educational project is a complex and difficult task that requires a number of particular conditions and the minimum of resources. They advice, that the project's target should be based on fundamental educational values and shared by all educators. They must be defined in operational objectives and translated into action for the educational project can give the expected results.

Sports taught (44\%), With reference to Ade et al. (2007), many studies have shown the links between knowledge, action, the production context of this action, and the experience. Ade et al. (2007) notice that PE-ST can be brought to teach a sports discipline for which he received no training. Conversely, he can teach sports disciplines for which he received sustained training throughout his curriculum, and build knowledge elements in his 
experience as a practitioner or an educator in a sports club. They add that the degree of specialization in the discipline affects the teacher's activity.

Too often, the choices of sports during physical education lessons do not reveal the characteristics of girls and boys as is the case when offering a basket-ball or hand-ball (Kino-Québec, 1997; Lenskyj, 1994).

According to Bégin (2011) several sources of motivation were identified by the teenagers: to live social interactions, fun, activities where they feel the valuation, exclusive physical activities for girls and the possibility of choice. In short, if teachers could insert these ingredients into their lesson planning, it is likely that teenage girls would be more motivated to participate.

Influence of substances (40\%), Brossard (2012) demonstrated that adolescents who affiliate with deviant peers are more disengaged at school the following year. With reference to Brossard (2012), it's essential to be able to offer these adolescents the conditions in school environments that can protect them against delinquency. To the extent that psycho-education specializes in children and adolescents in adjustment difficulties as well as in the animation of group activity, the psycho-educator certainly has a role to play in improving the favorable conditions so that the extracurricular activities can contribute to the involvement and academic success of our teenagers.

And external influences (38.7\%), According to Boissonneault (2007) a large number of personal, family and school variables affect dropouts or students experiencing behavioral problems. He points out that the support and guidance received by the young on the part of his family members to stay in school or not affect his motivation to continue his studies. Also the relationships between students with school staff may be a risk or protective factor. Boissonneault (2007) foresees that a member of non-teaching staff can make a thourough difference to a young. The school size and class contributes to the protection or to the risk it is thought to offer according to whether or not it promotes learning.

\section{Conclusion}

This study will deepen our knowledge with respect to the characteristics of non-student participation in the physical education session. In this study, we will be able to identify the major variables that are associated with the abondan of physical activity. However, we recognize that this study has limitations and that some issues will arise concerning young adults towards the regular practice of physical activities.

In this study, we will attempt to establish an overview of the problematic related to the non-participation of students in the physical education session. This exercise will lead us to question our practices and propose new interventions tracks for Tunisian physical education teachers. In the first category of analysis, our results indicate that teacher characteristics, relationship with other students, motivation, Relationship with teacher, menstrual period, season and lesson content are significantly associated factors to no-participation of students in the physical education session. Moreover, Infrastructure, Sports taught influence of substances and hourly and external influences are direct predictors of intentions to practice various physical activities.

Identifying predominance of variables allowed us to target key elements that physical educators can guide their actions in order to make them more effective. This study also enhances our level of understanding of this complex phenomenon, or non participation of students in the physical education session. Thus, physical educators will be able to organize their practice strategically and optimize the impacts on students. We have successfully demonstrated that the teachers' behavior influences at different levels students' practices. However, much remains to be done and challenges in order to promote an active way of teaching.

This study has interesting implications in the field of professional training and education in general. It must be noted that motivation and school retention are hot topics. They are the concern of most interveners in the field of education.

\section{References}

Adé, D., Sève, C., \& Serres, G. (2007). Familiarity with the Sport Taught and Forms of Activity in a Physical Education Teacher Intern: An Exploratory Study. 76, 51-66.

Averill, J. (1982). Anger and Agression: An Essay on Emotion. New York: Springer-Verlag. http://dx.doi.org/10.1007/978-1-4612-5743-1

Ayme, S., Ferrand, C., \& Cogérino, G. (2012). Deviant Behavior of Pupils and Emotion of Anger Teachers EPS. Crossroads of Education, 32, 221-235. 
Bali, N. (2005). “Theory and Practice” Articulation in the Training of Tunisian Student Physical Education Teachers. The Journal of Research and Training, 49, 135-150.

Bali, N. (2013). Teachers’ Thought Processes: The Case of Tunisian Gymnastic University Teachers. Creative Education, 4, 77-84. http://dx.doi.org/10.4236/ce.2013.47A2020

Bali, N. (2015). The Tunisians Cooperative Teachers and Student Teachers' Conceptions about Class Management Skill. Creative Education, 6, 87-99. http://dx.doi.org/10.4236/ce.2015.61008

Bali, N. et al. (2013). The Conceptions of Authority of Tunisian Physical Education Cooperative Teachers and Student Teachers. Conference Proceedings of the 7th Biennial ARIS.

Bali, N. et al. (2014). The Conceptions of Integration of Tunisian Physical Education Cooperative Teachers and Student Teachers. Creative Education, 5, 279-289. http://dx.doi.org/10.4236/ce.2014.54037

Bégin, J. (2011). Motivation for the Practice of Physical Activity among Adolescents in the Context of Dance and Physical Education.

Boissonneault, J., Michaud, J., Côté, D., Tremblay, C., \& Allaire, G. (2007). The Drop in French Ontario and Future Prospects of Young People. Education and Francophonie, 35, 3-22.

Boucher, L. P., \& Morose, J. (1990). Accountability and Ownership: The Dynamics of an Educational Project. Review of Education, 16, 415-431.

Brau-Antony, S. (2001). Teachers' Conceptions of Physical Education on Teaching and Evaluation of Collective Sports Games: Results of a Survey. Staps, 56, 93-108. http://dx.doi.org/10.3917/sta.056.0093

Brossard, M. (2012). The Moderator Role of Participation in Extracurricular Activities in the Relationship between Deviance Friends and Behavioral Disengagement among Adolescents.

Caplette-Charette, A. (2014). The Physical Education College and the Self-Efficacy of Girls.

Cèbe, S., \& Goigoux, R. (1999). The Influence of Teaching Practices on Student Learning Difficulties. Cahiers Alfred Binet, 661, 49-68.

Cloes, M. (2013).The Schoolmaster and Promoting Physical Activity. (In Seminar)

Cloes, M., \& Piéron, M. (1989). Identification of Enthusiastic Teacher Behaviors Perceived by Students during Physical Education Sessions. Journal of Physical Education, 29, 7-16.

Cloes, M., Demblon, S., Pirottin, V., Ledent, M., \& Piéron, M. (1998). Characterization of the Most Significant Discipline Incidents Experienced by Teachers in Physical Education. The Journal Physical Education, 38, 69-82.

Coltice, M. (2005). Dance and Gender Identity in EPS. In G. Cogérino (Ed.), Alles and Boys in EPS (pp. 101-124). EPS Review.

Debarbieux, E., Anton, N., Astor, R. A., Benbenishty, R., Bisson-Vaivre, C., Cohen, J., \& Giordan, A. (2012). The "School Climate": Definition, Effects and Conditions for Improvement. Report to the Scientific Committee of the School Education Directorate, Ministry of National Education, MEN-DGESCO/International Observatory on Violence in School.

Degrandpré, L., \& Paquet, F. (2006). Impact of a Physical Training Program on Psychological Health, Cognition and Academic Performance. Research Report of the Association of Private Colleges of Quebec, 60 p.

Lemoyne, J., \& Valois, P. (2014). Predictors of the Practice of Physical Activity among College Students. Canadian Journal of Behavioural Science, 46, 262-274. http://dx.doi.org/10.1037/a0030221

Lenskyj, H. (1994). The Woman, Sport and Physical Activity. Sport Canada: Documentation Centre for Sport, 51 p.

Moreno, J., Cervelló, E., \& Martinez Galindo, C. (2007). Perception of Discipline Selon Gender, Kind of School, Sports Activity and Interest in Physical Education in Spanish Students. International Journal of Applied Sports Sciences, 19 , 35-49.

Nolin, B., \& Hamel, D. (2005). Quebecers Moving More but Still Not Enough. In M. A. Venne Robitaille (under the Direction of), Quebec's Yearbook 2006 (pp. 296-311). Montreal: Fides.

Vallerand, R. J. (1997). Toward a Hierarchical Model of Intrinsic and Extrinsic Motivation. Advances in Experimental Social Psychology, 29, 271-360. http://dx.doi.org/10.1016/s0065-2601(08)60019-2

Van Zanten, A. (2001). The School in the Periphery, Education and Segregation in the Suburbs. Paris: PUF.

Warburton, D. E., Katzmarzyk, P. T., Rhodes, R. E., \& Shephard, R. J. (2007). Evidence-Informed Physical Activity Guidelines for Canadian Adults. Canadian Journal of Public Health, 98, 16-68. 


\section{Submit or recommend next manuscript to SCIRP and we will provide best service for you:}

Accepting pre-submission inquiries through Email, Facebook, LinkedIn, Twitter, etc.

A wide selection of journals (inclusive of 9 subjects, more than 200 journals)

Providing 24-hour high-quality service

User-friendly online submission system

Fair and swift peer-review system

Efficient typesetting and proofreading procedure

Display of the result of downloads and visits, as well as the number of cited articles

Maximum dissemination of your research work

Submit your manuscript at: http://papersubmission.scirp.org/ 